\title{
Wealthwide now launched in \\ the UK with a vision to help dentists gain financial freedom and get more out of life
}

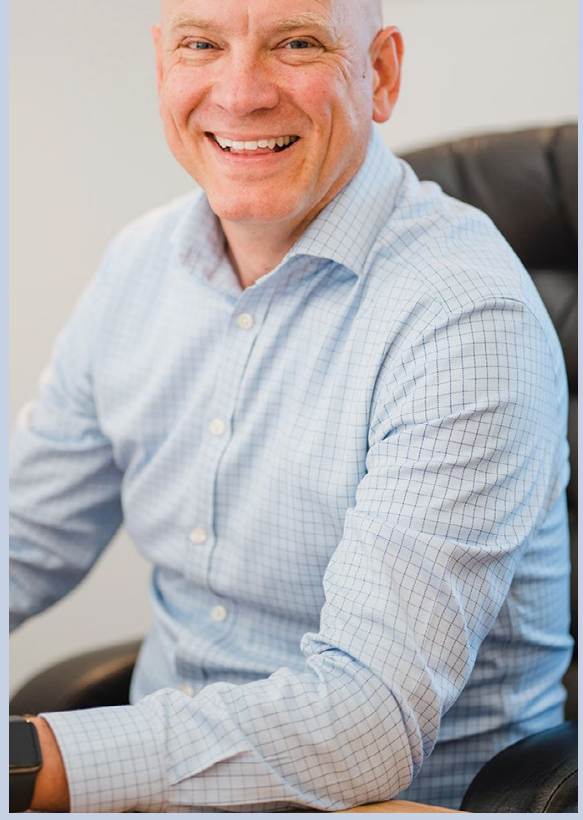

Thomas Dickson

Wealthwide helps dentists see their full financial picture so they can get more out of life. It is the vision of Thomas Dickson, who has specialised in working with dentists for over 20 years and decided to rebrand from Essential Money to Wealthwide. Thomas and his team worked with gutsy creative agency StudioLR to develop the Wealthwide brand.

Wealthwide's focus is to help dental professionals see the full extent of their financial picture. This allows them to plan to do the things they really want to in life, with security and peace of mind - swapping long hours for long weekends, overtime for family time, last-minute appointments for lastminute adventures, and the dentist's chair for a deck chair.

Wealthwide's planning services enable dentists to understand their financial options so that they can make life choices with confidence and security.

Wealthwide planning can help answer all sorts of tricky questions, such as:
- When can I afford to stop working?

- What rate of investment return do I need to do all the things I hope to do?

- Can I afford to sell my practice?

- Will downsizing my home in the future release enough funds to support my retirement?

- Will I still be able to live comfortably if I give money to my children?

Thomas Dickson, Managing Director of Wealthwide, explains: 'The last 18 months have been a real challenge for many of our clients. The lockdowns and change in working practices have led many dentists to reconsider their position and longer-term future.

'Our rebrand to Wealthwide makes it absolutely crystal clear what we can do for our clients. We help dentists to question what they really want from life, to fully understand their financial position and make the big life decisions based on hard facts. We call this process "financial planning", and it ensures we consider the wider picture and can help our clients create the work-life balance they deserve. The team at Wealthwide has been working with dentists for over two decades and are excited about what they can do in the next decade.'

Thomas is very aware that the coronavirus pandemic has had a significant financial impact on the dental profession. Requests from dental students, dentists and their families seeking help from the BDA Benevolent Fund increased 120\% in 2020 compared to the previous year. This coincided with a reduction in donations from dentists both through individual giving and fundraising events. In recognition of this, Wealthwide is pledging $£ 5,000$ to the charity.

BDA Benevolent Fund General Manager, Laura Hannon, comments: 'Wealthwide's donation will allow us to provide necessary support such as contributions towards rent or mortgages, food and household bills for those who cannot afford it at this time and helping them to move forward'.

To add your support to this cause and help those in the profession who are struggling, visit https://www.bdabenevolentfund.org.uk/ donate/.

For more information about Wealthwide, visit www.wealthwide.co.uk.

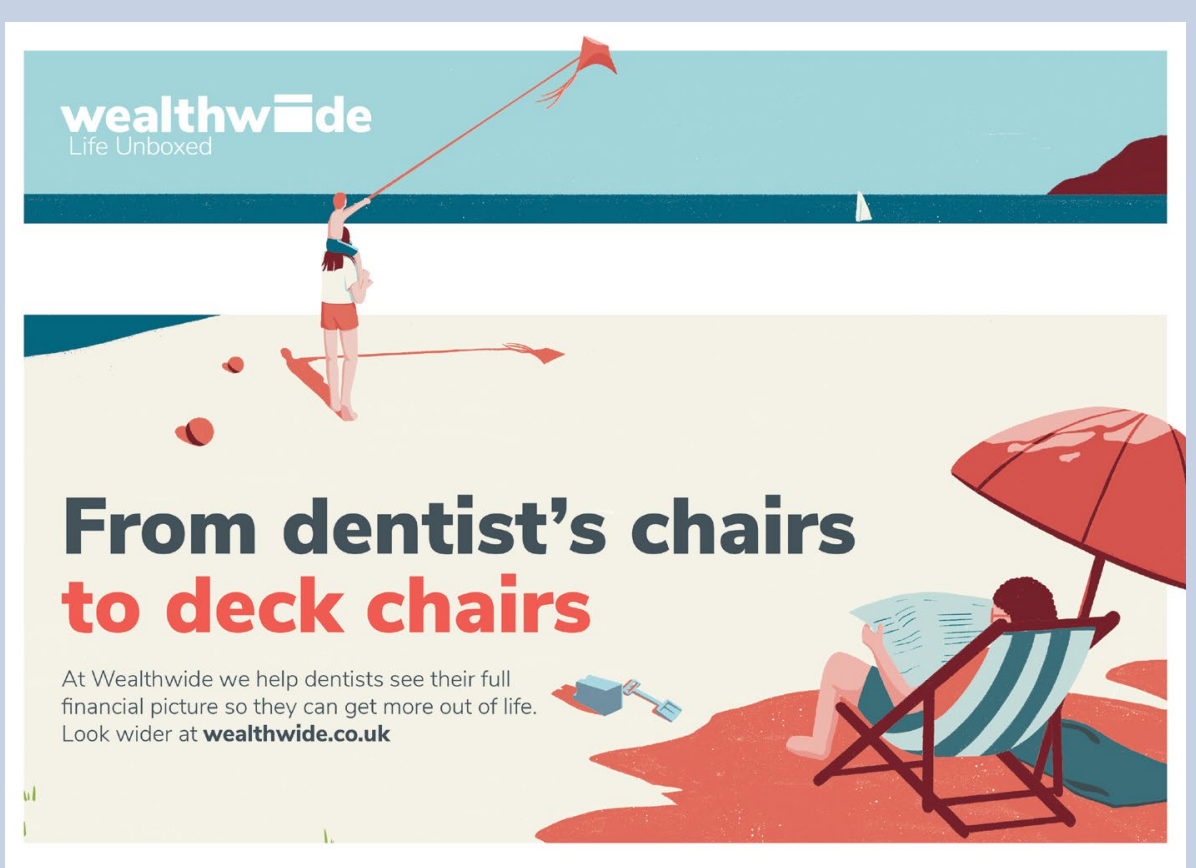

